\title{
PERANCANGAN POSTER BENTUK WAYANG KRESNA GAGRAK SURAKARTA
}

\author{
Devi Ariyanti, Puji Anto \\ Desain Komunikasi Visual \\ Fakultas Bahasa dan Seni, Universitas Indraprasta PGRI \\ Jl. Nangka 58 Tanjung Barat, Jakarta Selatan, Indonesia \\ deviariyanti7911@gmail.com
}

\begin{abstract}
Abstrak
Pada perancangan poster ini bertujuan untuk memberikan pengetahuan tentang bentuk wayang Kresna Gagrak Surakarta. Tulisan ini merupakan hasil dari penelitian yang dilakukan berdasarkan minimnya penelitian dan referensi akademik yang mengulas tentang Bentuk Wayang Kresna. Maka diperlukan media yang dapat mengidentifikasikan bentuk dari wayang Kresna. Jenis tipografi yang digunakan adalah jenis huruf Trajan Pro 3 dan Segoe UI. Menggunakan warna warna hitam pada font, kemudian bagian latar belakang menggunakan warna cream dan cokelat. proses perancangan poster ini, membuatnya dengan menggunakan aplikasi Adobe Ilustrator. Jenis layout Picture Window Layout dimana jenis ini, tampilan gambar yang besar menjadi suatu keutamaan dan keterangan gambar yang kecil masih bisa dibaca dengan baik. Penggunaan media poster ini diharapkan dapat membantu untuk memberi wawasan tentang bentuk bentuk Wayang Kresna Gagrak Surakarta.
\end{abstract}

Kata Kunci: Wayang, Kresna, Bentuk, Surakarta, Media

\begin{abstract}
In the design of this poster aims to provide knowledge about the form of Kresna Gagrak Surakarta puppet, it is necessary for the media to identify the form of the Kresna puppet. The type of typography used is the type Trajan Pro 3 and Segoe UI. Use the black color on the font, then the background using cream and brown. the process of designing this poster, makes it using an application that is using Adobe Illustrator. Type of layout Picture Window Layout where this type, the large image display becomes a priority and a small picture description can still be read well. The use of poster media is expected to help to provide insight into the form of Surakarta Kresna Gagrak form.
\end{abstract}

Keywords: Puppet, Kresna, Shape, Surakarta, Media

\section{PENDAHULUAN}

Hazeu mengatakan bahwa wayang dalam bahasa/kata Jawa berarti: bayangan, dalam bahasa melayu artinya: bayang-bayang, yang artinya bayangan, samar-samar, menerawang (Mertosedono, 1994: 28). Wayang juga merupakan gambaran kehidupan manusia konkret dengan segala sifat karakter-karakter unik yang ada pada aneka ragam manusia individual, partikular. Kehalusan batin yang terwujud dalam perilaku bijaksana ataupun perilaku angkara murka dari kecantikan batin dapat terungkap dan tercermin dalam tokoh-tokoh pe-wayangan Jawa.

Wayang kulit purwa merupakan salah satu jenis wayang kulit paling populer daripada jenis wayang kulit yang lain, seperti wayang Madya, Gedhog, Dupara, Perjuangan, Suluh, Wahyu, 
Warta, dan Sadat. Hal ini di samping wayang kulit Purwa telah berusia panjang, juga secara artistik telah mengalami puncak keemasan atau dengan kata lain bentuk wayang kulit purwa telah dianggap mapan (Jawa: adiluhung).

Wayang Kulit Purwa saat ini dapat dikatakan telah mencapai bentuk puncaknya (klasik, adiluhung). Hal tersebut terjadi karena wayang kulit purwa telah mengalami berbagai macam perubahan, yaitu dari segi materi atau bahan yang digunakan dalam membuat wayang, teknik perwujudannya, dan bentuk anatominya. Perubahan Wayang Kulit Purwa tersebut terjadi karena berbagai aspek, terutama masalah peradabandan kebudayaan masyarakat.

Meskipun bentuk wayang kulit purwa masing-masing daerah (Cirebon, Kedu, Yogyakarta, Surakarta, dan Jawa Timuran) berbeda, tetapi peran yang digambarkan tetap terdapat kesankesan. Misalnya tokoh Werkudara, baik gaya Cirebon Kedu, Yogyakarta, Surakarta, maupun Jawa Timuran pasti memiliki kesamaan penggambaran: bertubuh tinggi besar, memakai pupuk mas, bergelung minangkara, berkuku pancanaka, berkain poleng bang bintulu, dan sebagainya. Hal itulah yang menyamakan persepsi kita pada tokoh-tokoh wayang kulit purwa (Suwarno, tanpa tahun: 1).

Acuan perancangan sosok karakter pada tampilan, kepribadian tokoh karakter yang sesuai dengan cerita, dan kemampuan rancangan karakter tersebut dalam mempre-sentasikan dalam bentuk visualnya ( Saptodewo, 2016).

Dalam konteks penelitian ini, peneliti merancang sebuah media informasi berupa poster yang dianggap cukup efektif dalam mengomunikasikan informasi. Dalam kompetensi desain komunikasi visual adalah suatu disiplin ilmu yang mempelajari konsep-konsep komunikasi serta ungkapan kreatif melalui berbagai macam media untuk menyampaikan suatu pesan dan gagasan secara visual dengan mengelola elemen-elemen grafis yang berbentuk gambar, tatanan huruf, warna, dan layout (Kusrianto, 2007: 2). Peneliti akan membuat sebuah desain poster yang menghubungkan beberapa unsur sehingga dapat menyampaikan pesan dengan baik.

Tujuan dari perancangan poster ini menghasilkan sebuah perancangan poster dengan menggunakan desain dan bahasa yang tepat, sehingga menghasilkan sebuah produk yang bermanfaat dan tepat pada sasaran yang dituju (Subianto, Anto, Akbar, 2018). Poster ini bertujuan untuk memberikan pengetahuan tentang bentuk wayang Kresna Gagrak Surakarta, maka diperlukan media yang dapat mengidentifikasikan bentuk dari wayang Kresna. Dengan adanya media informasi berupa poster ini dapat diharapkan masyarakat dapat memiliki wawasan mengenai bentuk wayang Kresna Gagrak Surakarta.

\section{METODE PENELITIAN}

Tulisan ini merupakan hasil dari penelitian yang dilakukan berdasarkan minimnya penelitian dan referensi akademik yang mengulas tentang Bentuk Wayang Kresna.

Penelitian yang dilakukan menggunakan jenis penelitian kualitatif, menurut pandangan Strauss dalam Ratna (2010: 97), kualitatif adalah peneliti dalam dirinya sendiri atau dalam pengertian lain yaitu bricolor, manusia serba bisa atau seorang pribadi yang mandiri dan profesional. Dari pengertian tersebut, Denzin dan Lincoln menjelaskan lebih lanjut bahwa proses kualitatif merupakan proses interaktif yang dibentuk sejarah personal, biografi, gender, kelas sosial, ras, etnis dan sebagainya, dengan sudut pandang yang berbeda sebagai perbedaan gaya, epistemologi, dan representasi (Ratna, 2010: 101).

\section{HASIL DAN PEMBAHASAN \\ Prabu Kresna}

Kresna adalah raja Dwarawati. Waktu masih muda, ia dipanggil Narayana. Dalam pewayangan Indonesia, sebutan Batara Kresna disebabkan karena merupakan titisan Batara Wisnu. Oleh sebab itu, dalam keadaan terdesak atau marah, raja Dwaramati dapat melakukan triwikrama, yakni mengubah diri menjadi raksasa yang amat besar, sakti, dan tanpa lawan.

Kresna adalah putra kedua Prabu Basudewa dari negeri Mandura, kakaknya bernama Baladewa, ketika dewasa mewarisi kedudukan ayahnya sebagai raja. Ibunya mereka bernama Dewi Mahendra. Adiknya yang bernama Subrada atau Bratajaya, dilahirkan oleh Dewi Badraini. 
Kelak, Bratajaya diperistri oleh Arjuna. Ketika kecil mereka bertiga diasuh oleh Demang Antagopa dan Nyai Sagopi di Kademangan Widarakandang.

Selama berada di Widarakandang inilah secara diam-diam Narayana berguru kepada

Maharesi Padmanaba, di Padepoan Girikastuba. Karena ketekunannya belajar, suatu hari Maharesi Padmanaba menghadiahi Narayana dua buah pusaka. Yang berwujud senjata bernama Cakra Baskara, sedangkan yang lain berupa bunga bernama Cangkok Wijayakusuma. Setelah itu Maharesi Padmanaba muksa (gaib, menghilang) dan menyatu pada diri Narayana. Sesungguhnya Maharesi Padmanaba adalah penjelmaan Batara Wisnu.

Senjata pusaka Prabu Kresna yang bernama Cakra Sudarsana, berupa anak panah. Dalam pewayangan mata panah Cakra berwujud seperti roda bergerigi. Senjata pemusnahan yang merupakan senjata titisan Dewa Wisnu itu mempunyai banyak kegunaan, tergantung kemauan pemiliknya. Selain itu, Kresna juga mempunyai pusaka lain berupa bunga Cangkok Wijayakusuma yang berkhasiat dapat menghidupkan orang mati, asalkan orang itu belum sampai pada takdirnya. Kresna juga memiliki kemampuan untuk mengetahui segala hal yang akan terjadi. Dalam pewayangan, yang menyebabkan Kresna tahu sebelum terjadi adalah karena ia memiliki Kaca Lopian atau Kaca Paesan (Solichin, Suyanto, dan Sumari, 2017).

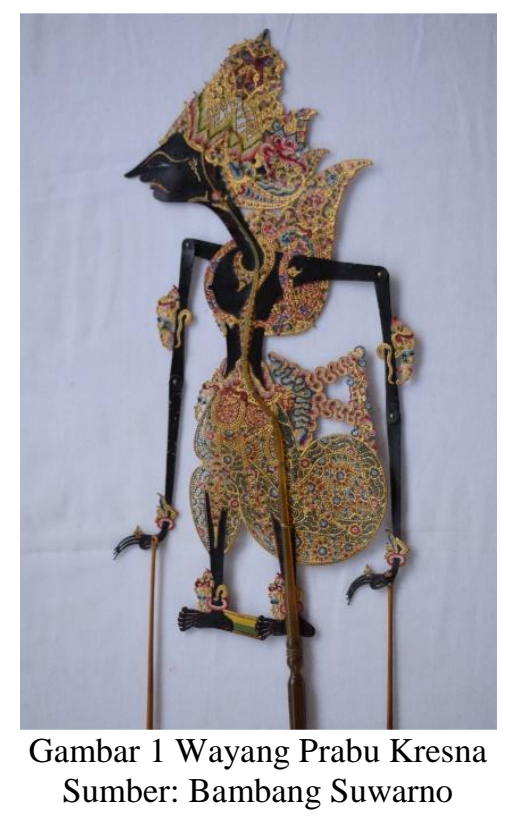

\section{Rupa Wayang Kresna}

Dalam seni rupa wayang kulit purwa, Kresna tergolong tokoh wayang yang mempunyai banyak wanda. Kresna wanda Rondhon, mukanya agak tunduk ke bawah, kecondongan lehernya mayat, kedua bahunya agar datar, mahkotanya terpasang tegak. Wanda ini diciptakan tahun 1605 Jawa, pada zaman Sunan Amangkurat Seda Tegalarum.

1. Hidung, Kresna memiliki bentuk hidung Wali Miring, bentuk hidung ini diperuntukan bagi tokoh wayang purwa yang bertubuh kecil.

2. Mata, Kresna memiliki bentuk mata liyepan (mata gabahan) wujudnya menyerupai bentuk biji gabah (biji padi), yang belum dikupas kulitnya. Jenis mata liyepan ini digunakan oleh tokoh wayang yang bertubuh kecil, langsing, yang memancarkan sifat atau watak bertubuh luhur, bijaksana.

3. Mulut, Kresna memiliki bentuk mulut mingkem dalam perwayangan untuk menggambarkan mulut dalam keadaan "mingkem" (bibir atas dan bibir bawah tertutup rapat). Pada umumnya tokoh wayang yang bermulut mingkem adalah mempunyai kemampuan yang luar biasa dan mempunyai kekuatan yang tidak terbatas. Biasanya bermata liyepan dan berhidung wali miring. 
4. Dahi, Kresna memiliki bentuk dahi Bathukan lugas.

5. Leher, Kresna memiliki bentuk leher Jangga mayat. Jangga mayat, yaitu posisi leher condong ke depan lebih dari 22,5 derajat.

6. Perut, Kresna memiliki bentuk perut Mbangkek. Mbangkek yaitu perut yang tampak datar singsat.

7. Tangan, Kresna memiliki bentuk tangan nyempurit, cempuritan atau sumpit, yaitu tangan yang kelihatan tiga jari dengan telunjuk melingkar pada ibujari.

\section{Busana Wayang Kresna}

Pada bentuk anatomi wayang kulit purwa secara keseluruhan, busana wayang merupakan bagian yang terlihat paling dominan, karena hampir seluruh bagian anatomi tubuh wayang kulit purwa terbalut oleh busana dan perlengkapannya. Seperti pada seorang manusia, wayang kulit juga diperindah dengan busana. Akan tetapi bentuk busana pada wayang kulit purwa menyatu dengan unsur-unsur yang lain pada sebuah proses tatah sungging (Murdiyanto, 2006: 6).

Busana wayang kulit purwa memiliki jenis-jenis yang beranekaragam. Menurut Bambang Suwarno (2005:39).

1. Irahan, Kresna menggunakan irah-irahan makutha kencana.

2. Garudha Mungkur, ada yang bermata satu dan bermata dua. Adapun Utah-utahnya ada tiga macam yaitu, karawistha cekak, karawistha panjang, segaramuncar. Kresna menggunakan karawistha cekak.

3. Kalung Ulur, Kalung terdiri dari ulur naga karangrang, pananggalan, kebomegah, kaweng gedhong atau kaweng wastra, kace atau kacu, kencana, gentha, bandhul. Kresna menggunakan kalung kencana

4. Kroncong, terdiri dari dhapur nagaraja, dhapur naga, binggel. Kresna menggunakan kroncong dhapur muka.

5. Kelat Bahu, digunakan oleh Kresna adalah nagamangsa, biasanya nagamangsa ini digunakan oleh para raja, ksatria, maupun para putri.

6. Gelang, Kresna menggunakan gelang susun kana rangkep gangsa calumpringan.

7. Cincin, digunakan seperti wayang-wayang lain yaitu gunung sepikul.

\section{Perancangan}

Berikut merupakan konsep media yang digunakan dalam perancangan poster tentang perancangan bentuk wayang Kresna gagrak Surakarta.

Tipografi

Penggunaan huruf pada poster ini lebih mengutamakan readability (keterbacaan sebuah huruf). Oleh karena itu, penulis memilih jenis huruf Trajan Pro 3 dan Segoe UI . Pada jenis huruf Trajan Pro 3 adalah jenis huruf serif yang memiliki kait atau kaki. Pada jenis huruf Sageo UI adalah jenis huruf sans-serif yang tidak memiliki kait atau kaki dan secara kontur hurufnya lebih modern.

\section{Warna}

Warna merupakan elemen yang sangat penting. Karena warna dapat memberikan efek cahaya yang memberi kesan pada mata, sehingga dapat mengahadirkan karakter dari suatu bentuk yang secara psikologis mempengaruhi perasaan (Wayan, 2010). Warna yang akan digunakan pada poster ini menggunakan warna hitam pada font, kemudian bagian latar belakang menggunakan warna cream dan cokelat.

Warna hitam digunakan karena karakter dari Kresna adalah berkulit hitam. Menurut Suwarno Kresna berarti berkulit hitam, kresna juga memiliki darah hitam (Wawancara, 19 Oktober 2018). Maka dari itu pada warna dalam huruf digunakan berwarna hitam selain agar dapat terlihat jelas, warna hitam ini diambil dari karakter Kresna sendiri. Warna cokelat dimbil karena melambangkan budaya jawa, dan dapat dilihat dari kain batik yang berwarna coklat. 


\section{Perancangan Poster}

Berdasarkan data, dapat dijadikan dasar Perancangan Poster Bentuk Wayang Kresna Gagrak Surakarta.Pada proses perancangan poster ini, membuatnya dengan menggunakan suatu aplikasi yaitu menggunakan Adobe Ilustrator. Dengan ukuran kertas A4 atau 21 x 29,7 cm. Ukuran font menyesuaikan keterbacaan pada poster. Untuk pewarnaan menggunakan metode CMYK. Untuk layout yang digunakan, menggunakan jenis layout Picture Window Layout. Pada jenis ini, tampilan gambar yang besar menjadi suatu keutamaan dan keterangan gambar yang kecil masih bisa dibaca dengan baik.

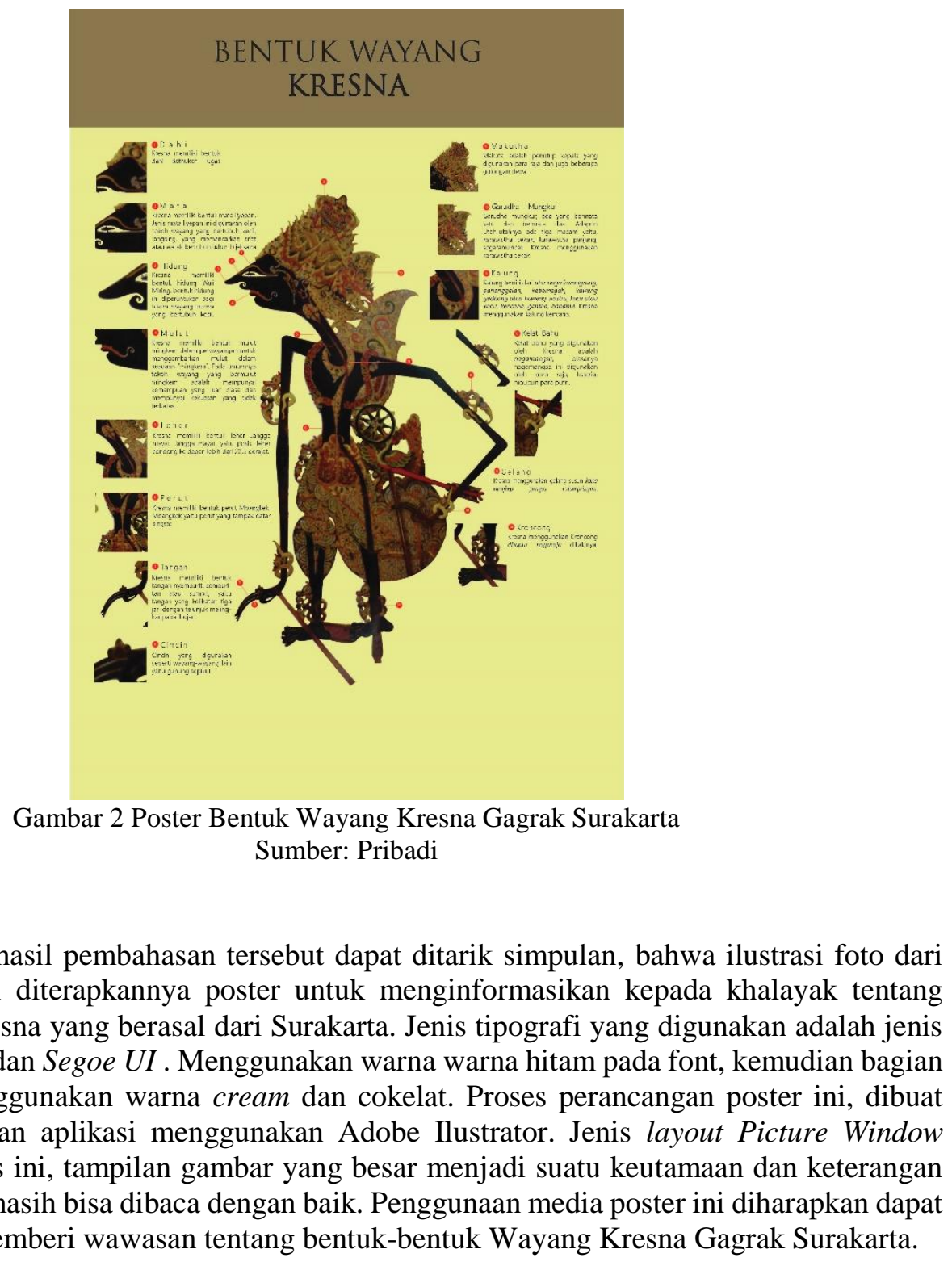

\section{SIMPULAN}

Berdasarkan hasil pembahasan tersebut dapat ditarik simpulan, bahwa ilustrasi foto dari Wayang Kresna ini diterapkannya poster untuk menginformasikan kepada khalayak tentang bentuk Wayang Kresna yang berasal dari Surakarta. Jenis tipografi yang digunakan adalah jenis huruf Trajan Pro 3 dan Segoe UI . Menggunakan warna warna hitam pada font, kemudian bagian latar belakang menggunakan warna cream dan cokelat. Proses perancangan poster ini, dibuat dengan menggunakan aplikasi menggunakan Adobe Ilustrator. Jenis layout Picture Window Layout dimana jenis ini, tampilan gambar yang besar menjadi suatu keutamaan dan keterangan gambar yang kecil masih bisa dibaca dengan baik. Penggunaan media poster ini diharapkan dapat membantu untuk memberi wawasan tentang bentuk-bentuk Wayang Kresna Gagrak Surakarta.

\section{DAFTAR PUSTAKA}

Mertosedono, A. (1986). Sejarah wayang: Asal-usul, jenis dan cirinya. Semarang: Dahara Prize.

Solichin, H., Suyanto, Sumari, Wiyono, U., \& Purwato, S. (2017). Ensiklopedi wayang Indonesia. Bandung: Mitra Sarana Edukasi.

Suwarno, B. (2005). Teknik Pembuatan Wayang Kulit Purwa Gaya Surakarta. Jakarta: Senawangi. 
Saptodewo, F. (2016). Perancangan bentuk tokoh wayang tetuka Saat balita. Jurnal Desain, 3(01), 21-26.

Subianto, I. B., Anto, P., \& Akbar, T. (2018). Perancangan Poster sebagai Media Edukasi Peserta Didik. Jurnal Desain, 5(03), 215-222.

I Wayan, G. (2010). Pengertian Warna dan Tekstur. Diakses dari http://repo.isidps.ac.id/143/1/Pengertian_Warna_dan_Tekstur.pdf 